specimens studied during the period 1971-81 (about 1\% of the population has to be excreting a virus before it is usually detectable in sewage).

As soon as the widespread distribution of poliovirus type 3 throughout the country became evident, about the end of November, the health authorities recommended an extra dose of the regular Salk type trivalent oral poliovirus vaccine for all children under the age of 18 years. The extra vaccinations were started from the younger age groups as it is known from recent antibody prevalence studies that many small children do not have measurable antibodies to poliovirus type 3 and that the prevalence of antibodies increases with age and further booster doses of vaccine, so that almost all adults appear to have antibodies to poliovirus type 3 . In addition, the Finnish authorities have decided to vaccinate the entire population, nearly five million people, through a mass campaign using the live attenuated poliovirus vaccine (Sabin). Immunocompromised patients and their household contacts will be given one dose of inactivated poliovirus vaccine first.

\section{Comment}

In a review in 1982 of the effects of inactivated poliovirus vaccine on poliovirus immunity in Finland Lapinleimu tested 1463 people for poliovirus antibody. ${ }^{1}$ Antibody to poliovirus type 3 was detectable in only $47-60 \%$ of children aged 1 to 6 years, and to type 1 in 62 $67 \%$, compared with $83-93 \%$ to type 2 . Even in older children aged 7 to 14 years - after one or two booster doses-the levels were $76-85 \%$ for type 3 and $80-88 \%$ for type 1 compared with $95-98 \%$ for type 2 . Although a booster type response was seen after further doses given to 14 children without antibody to type 1 and 10 without antibody to type 3, suggesting that they were already immune, it is of interest that the present outbreak was caused by a type 3 strain, the strain to which lowest immunity levels were detected.

Nevertheless, no clear explanation has been found for the widespread circulation of a poliovirus type in a country in which high immunisation levels have led to virtual absence of the virus or the disease for 20 years. Dr G C Schild (National Institute of Biological Standards and Control) has examined the Finnish strains and found them to be poorly neutralised by antibodies to the classical vaccine strain of poliovirus type 3 , providing some evidence that antigenic evolution has occurred in this virus. Although the existing preparation of inactivated poliovirus vaccine in Finland was considered to be effective enough, a more potent Dutch inactivated poliovirus vaccine was to be substituted from 1986 , but this change is now being brought forward to 1985 .

Prepared by the PHLS Communicable Disease Surveillance Centre, 61 Colindale Avenue, London NW9 5EQ, based on a report from the National Public Health Institute, Finland

\section{Reference}

1 Lapinleimu K. Killed poliovirus vaccine in the control of poliomyelitis in Finland. Ann Clin Res 1982;14:199-203.

\title{
Apparent portosystemic encephalopathy in patients with chronic liver disease
}

\author{
C C KIBBLER, G P JEFFREY, O EPSTEIN, N MCINTYRE
}

Portosystemic encephalopathy is a common cause of admission to hospital in patients with chronic liver disease and is characterised by confusion, alteration in the degree of consciousness, and a flapping tremor. We report three cases of apparent encephalopathy seen at our hospital during the past year in which the clinical features were the result of widely differing neurological disorders.

\section{Case 1}

A 47 year old man with cirrhosis related to hepatitis B virus infection began a course of endoscopic sclerotherapy in January 1984 . He received his fourth treatment in March and 10 days later was readmitted with malaise, drowsiness, and two transient episodes of right sided numbness. He had a

Academic Department of Medicine, Royal Free Hospital, London NW3 2QG C C KIBBLER, MRCP, medical registrar

G P JEFFREY, MRCP, medical registrar

O EPSTEIN, MRCP, lecturer in medicine

N MCINTYRE, FRCP, professor of medicine

Correspondence to: Dr O Epstein.
Cerebrovascular accident should always be considered in a patient with cirrhosis with an altered degree of consciousness

temperature of $38^{\circ} \mathrm{C}$ and was drowsy with hepatic fetor and a flapping tremor. No focal neurological signs were present. An electroencephalogram showed a mean frequency of $5.5 \mathrm{~Hz}$ with no interhemispheric asymmetry. He was treated with cefotaxime and metronidazole intravenously for presumed infection. Four days later he had a downward drift of the extended right arm. A technetium scan and computed tomogram of the head suggested herpes encephalitis, and he was therefore treated with acyclovir intravenously. His condition deteriorated; right facial weakness and asymmetrical pupils developed, and a repeat computed tomogram of the head showed a left temporoparietal abscess. After drainage and treatment with intravenous antibiotics he made a good recovery with minimal residual neurological deficit.

\section{Case 2}

In 1971 a 33 year old woman was found to have lupoid chronic active hepatitis with established cirrhosis. She was treated with prednisolone (30 
mg daily initially, $7.5 \mathrm{mg}$ daily maintenance dose), but her subsequent history was of regular admissions to hospital with fluid retention, bleeding oesophageal varices, and encephalopathy. She was readmitted in May 1984 with a two day history of drowsiness, headache, and vomiting. On examination she had a temperature of $39 \cdot 8^{\circ} \mathrm{C}$ and hepatic fetor. She was stuporous, responding only to painful stimuli, and had no stiffness of her neck, though Brudzinski's sign was present. No focal neurological signs were present. An electroencephalogram showed a mean frequency of $3.5 \mathrm{~Hz}$, compatible with encephalopathy, with no interhemispheric asymmetry. Lumbar puncture produced straw coloured cerebral spinal fluid containing $103 \times 10^{3}$ white blood cells/ $192 \%$ lymphocytes, $4 \%$ monocytes, and $4 \%$ neutrophils), which subsequently grew Listeria monocytogenes. She recovered completely taking ampicillin and netilmicin intravenously.

\section{Case 3}

A 68 year old man was investigated in May 1983 after developing spontaneous bruising. Liver biopsy showed splenomegaly and thrombocytopenia (platelet count $68 \times 10^{\circ} / 1$ ) with cryptogenic cirrhosis. In August he was readmitted with a 24 hour history of lethargy and confusion. On admission he was drowsy and disorientated. No flapping tremor was present, but he had a slight downward drift of the outstretched left arm. An electroencephalogram showed a mean frequency of $7 \cdot 5 \mathrm{~Hz}$, compatible with encephalopathy, and there was no interhemispheric asymmetry. In view of these findings computed tomography of the head was performed, which showed a large haematoma in the region of the right basal ganglia. He made an almost complete recovery over the next two weeks with conservative management.

\section{Comment}

The differential diagnosis of acute cerebral disorders in patients with cirrhosis, including alcoholics, is usually considered to be portosystemic encephalopathy, Wernicke-Korsakoff syndrome, withdrawal from alcohol, and subdural haematoma. ${ }^{1}$ The precipitating causes of portosystemic encephalopathy include gastrointestinal haemorrhage, increased intake of protein, drugs (sedatives and diuretics), disturbance of electrolyte concentrations, operations, and infection. ${ }^{2}$ The probable sites of infection are the urinary tract and, if present, ascitic fluid. Cases 1 and 2, however, show that infections of the central nervous system occur, and such infections have been described previously in patients with cirrhosis. ${ }^{34}$ They may be caused by unusual organisms such as Listeria monocytogenes, as seen in case $2 .{ }^{4}$
Cerebrovascular accidents are not uncommon among people aged over 60 . It was thought that cirrhosis carried a reduced risk of stroke, ${ }^{5}$ but recent data from France suggest that the incidence of intracerebral haemorrhage is increased in patients with cirrhosis. ${ }^{6}$ Although this association may be controversial, the possibility of cerebrovascular accident should always be considered in a patient with cirrhosis with an altered degree of consciousness, particularly an older patient.

Interestingly, the electroencephalograms in all three patients showed evidence of encephalopathy only, with no evidence of a focal lesion. Several explanations could account for this. Firstly, portable ward electroencephalography usually consists of a limited examination unless the technician is alerted to the possibility of a focal lesion. Secondly, all our patients had a degree of hepatic encephalopathy that may have masked other changes in the electroencephalogram. Thirdly, interpretation of the record may be suboptimal when portosystemic encephalopathy is expected. Indeed, re-examination of the electroencephalograms obtained in these patients by an independent electrophysiologist elicited abnormalities that are not usually seen in encephalopathy-for example, interhemispheric asymmetry-in two of the three cases.

A reduced degree of consciousness in a patient with chronic liver disease should not be assumed to be metabolic in origin, and the possibility of alternative diagnoses should always be considered, particularly when there are focal neurological signs or the encephalopathy is slow to respond to the usual measures.

We thank Professor Dame Sheila Sherlock and Professor H C Thomas for permission to report case 3 and case 1, respectively, and Dr R M Sherratt for independent assessment of the electroencephalograms.

\section{References}

1 Schomerus H. Differential diagnosis of acute cerebral disorders in alcoholism and cirrhosis. Internist (Berlin) 1981;22:555-61.

2 Sherlock S. Diseases of the liver and biliany system. 6th ed. Oxford: Blackwell Scientific Publications, 1983.

3 Lerner PI. Meningitis caused by streptococcus in adults. F Infect Dis 1975;131(suppl):9-16.

4 Kendall MJ, Clarke SW, Smith WT. Spinal abscess due to Listeria monocytogenes in a patient with hepatic cirrhosis. I Pathol 1972;107:9-11.

5 Kane WC, Aronson SM. Cerebrovascular disease in an autopsy population. 4. Reduced frequency of stroke in patients with liver cirrhosis. Trans Am Neurol Assoc 1971;96:259-60.

6 Boudouresques G, Hauw JJ, Meininger V, et al. Hepatic cirrhosis and intracranial hemorrhage: significance of the association in 53 pathological cases. Ann Neurol 1980;8:204-5.

(Accepted 20 March 1985)

\section{MATERIA NON MEDICA}

\section{Weekend Bolognese}

Bologna for two, over Whitsun, proved to be an admirable choice. Cool, colonnaded streets, handsome palaces, curious leaning towers, status symbols of a bygone era, provided much visual interest. A prosperous city, we felt, proud of its history and of its university.

Bologna gave us Marconi, to whom we are indebted for our radios. At an earlier period Thomas à Becket and the astronomer Copernicus were students of some distinction here. Then came Luigi Galvani, anatomist, obstetrician, and physiologist, who added "galvanism" to our language. In the square that bears his name he stands on his pedestal contemplating the hind legs of a frog. "To galvanize or not to galvanize" might have been written on the plaque beneath.

The old anatomy theatre in the Archiginnasio has been reassembled after severe war damage. It displays a galaxy of carved wooden figures set into the panelled ceiling and walls, the lecturer's canopy being upheld by two skinned wooden gentlemen, targets of ribald jokes by the students of the day.

On Saturday morning we set out for the university campus proper, hoping to visit the anatomical wax museum, and got lost. Then, a stroke of luck: I found a virologist to whom I explained the purpose of our visit. She more or less took us by the hand to the new anatomy building, about five minutes' walk away. There she vanished inside to reappear with the professor himself, who personally showed us round, spending nearly an hour over it. We were impressed that though it was a Saturday professor Mazzotti's department was properly staffed. He took us to Lelli's marbled gallery, displaying life size anatomical figures, wax modelled on bone, made by order of an 18th century pope. Another grand room contained 18th century pathological wax models, lovingly restored after wartime bombing. Tucked away under a showcase stood a box still holding grey, shapeless specimens as salvaged from the rubble.

Arguably the most interesting exhibit in wax was a self portrait by an anatomy professor's wife Anna Manzolini. Dressed up in all her finery, she shows herself lifting the dura off a brain. Anna must have been a formidable lady. When her husband died, in 1755 , she stepped into his post, becoming the new professor of anatomy. During his last illness her husband is said to have lost his reason, and it was this "madness" which stimulated her interest in the human brain. - $\mathrm{K}$ G HEYMANN, London.

WORDS Of the many Latin words for hair, two have medical connections. PILUs, now obsolete in English usage, remains with us in combining forms: PILOSEBACEOUS, PILOMOTOR, PILONIDAL; possibly pilocarpine (Gk pilos, wool+karpos, fruit); also buried within words as in DEPILATE, DEPILATORY, and CAPILLARY (L caput + pilus, hair of the head), whence slender and elongated like a scalp hair, when referring to a tube or blood vessel. ${ }^{1}$

Shaggy animal hair is villus in Latin, whence we have viLLUs, one of the innumerable hair like villi which give the intestinal mucosa a velvety $(\mathbf{L}$ villutus) surface. vELLUS (L fleece) is the fine body hair, excluding that which appears at puberty. VELOUR (Fr velvet) is a term that has been adopted from drapery to describe a special weave of Dacron for use in arterial prostheses. ${ }^{2}$ -B J FREEDMAN.

1 Freedman BJ. Words. Br Med f 1979;ii:262.

2 Kidson IG. Arterial prostheses. Br f Hosp Med 1983;30:248-54. 